\title{
УДК 336/63
}

\section{Л. Д. Медведева}

Новосибирский государственный университет экономики и управления, Новосибирск, e-mail: lusim@f117.ru

\section{О ВВЕДЕНИИ ЦИФРОВОГО РУБЛЯ В ДЕНЕЖНОЕ ОБРАЩЕНИЕ РОССИИ}

Ключевые слова: цифровой рубль, криптовалюта, форма денег, электронные деньги, коммерческие банки, денежно-кредитное регулирование, эмитент денег.

На основе анализа законодательных актов, аналитических документов Банка России, изучения научных публикаций обсуждаются и анализируются разные аспекты вводимой в денежное обращение России новой формы фиатных денег - цифрового рубля. Представлено место цифрового рубля в структуре существующих форм цифровых валют - электронных и виртуальных, определены их сущностные характеристики. Обозначена законодательная основа для введения цифрового рубля в денежное обращение, анализ которой позволяет сделать вывод о необходимости дополнения в закон определения цифрового рубля для четкого соотнесения цифрового рубля с существующими цифровыми валютами. Выделены особенности денежных функций цифрового рубля. Представлена характеристика модели реализации цифрового рубля принятая Банком России, определены функции субъектов-участников - Банка России и коммерческих банков. Акцентируется внимание на возможных рисках при функционировании данной модели: в области денежно-кредитного регулирования, связанный с киберпреступностью, с неопределенностью в части ликвидности коммерческих банков. Обоснованы рекомендации коммерческим банкам об активизации обеспечения финансовой грамотности субъектов настоящих и будущих клиентов. В заключении представлен план проектирования процесса введения цифрового рубля в денежное обращение России.

\section{D. Medvedeva}

Novosibirsk State University of Economics and Management, Novosibirsk, e-mail: lusim@f117.ru

\section{ON THE INTRODUCTION OF THE DIGITAL RUBLE INTO THE MONETARY CIRCULATION OF RUSSIA}

Keywords: Keywords: digital ruble, cryptocurrency, form of money, electronic money, commercial banks, monetary regulation, money issuer.

Based on the analysis of legislative acts, analytical documents of the Bank of Russia, the study of scientific publications, various aspects of the new form of fiat money introduced into monetary circulation in Russia - the digital ruble - are discussed and analyzed. The place of the digital ruble in the structure of existing forms of digital currencies - electronic and virtual - is presented, their essential characteristics are determined. The legislative basis for the introduction of the digital ruble into monetary circulation is outlined, the analysis of which allows us to conclude that it is necessary to supplement the definition of the digital ruble in the law for a clear correlation of the digital ruble with existing digital currencies. The features of the monetary functions of the digital ruble are highlighted. The characteristics of the digital ruble implementation model adopted by the Bank of Russia are presented, the functions of the participating entities - the Bank of Russia and commercial banks - are defined. Attention is focused on possible risks in the functioning of this model: in the field of monetary regulation, related to cybercrime, with uncertainty regarding the liquidity of commercial banks. The recommendations to commercial banks on the activation of financial literacy of the subjects of present and future customers are substantiated. In conclusion, a design plan for the introduction of the digital ruble into the monetary circulation of Russia is presented.

\section{Введение}

Информационные технологии стремительно меняют уклады в экономическом и социальном развитии современного мира. Парадигма цифровизации создает предпосылку для изменения всех сфер национальной экономики. Не является исключением и денежное обращение, где совсем скоро появится новый платежный инструмент - цифровая валюта центрального банка. Данный феномен является закономерным следствием высокой динамики обновления технологий проведения платежей, услуг мобильного банкинга и дистанционного банковского 
обслуживания. Роль денег, как посредника и эквивалента в экономическом и финансовом взаимодействиях, является ключевой, поэтому введение цифровых денег в условиях, когда ни в одной стране мира еще нет опыта их использования в реальном денежном обороте, является непростой, но важной задачей не только для банковской системы, но и для всего сообщества. Ее решение связано с широким обсуждением сущности нового вида денег и многоаспектным анализом областей противоречий. Основное из них противоречие между повышающимися требованиями субъектов, включая население и государство, к платежным средствам на основе современных технологий и обеспечением стабильного функционирования денежной и финансовой систем в условиях новых рисков при введении цифровой валюты. Инициатором обсуждения темы стал Банк России, который разработал и в октябре 2020 г. выпустил Доклад для общественных консультаций [1]. Данный документ представляет позицию Банка России по вопросам введения цифрового рубля в денежное обращение и одновременно базу для аналитических исследований, попытку которых представляет данная статья.

Цель работы: рассмотреть отдельные аспекты, выпуска цифрового рубля Банка России и выделить вопросы, которые необходимо решить для успешного его введения в денежное обращение без нарушения стабильности функционирования денежной и финансовой систем.

\section{Материалы и методы исследования}

В исследовании применен интеграционный подход к изучению эволюции и парадигм в сочетании с синкретной логикой мышления, методами сравнения и сопоставления процессов и явлений.

\section{Результаты исследования и их обсуждение}

В истории общественного развития деньги появились как результат поиска эквивалента и посредника обмена продуктами труда. За много веков они эволюционировали в диалектическом единстве форм: вещной, монетной, бумажной, электронной. Сегодня мы становимся участниками создания нового вида денег - виртуальных, которые наряду с электронными деньгами Банк России относит к блоку цифровых валют, а виртуальные валюты, в свою очередь, подразделяет на централизованные и децентрализованные [2, с.5]. В настоящее время в качестве виртуальных валют выступают криптовалюты. Среди них наибольшую популярность приобрел Bitcoin, который появился в 2009 году, а затем Ethereum, Litecoin, Ripple и другие альткоины, a позже стейблкоины, среди которых выделяется Libra2, созданный в 2019 году [3].

Электронные деньги определяется исследователями по-разному. Наиболее близким к нашим представлениям является определение, согласно которому электронные деньги представляют отраженное на компьютерных носителях информационное воплощение всеобщего эквивалента [4, с.103]. Что касается криптовалют, то в настоящее время существует уже достаточное количество публикаций, дающих представление об их сущности [4; 5; 6, 7 и др.]. Поскольку и электронные деньги и криптовалюты являются цифровыми деньгами, необходимо выделить их различия. Электронные деньги согласно закону являются традиционными денежными средствами, которые хранятся на электронном носителе и могут быть использованы в качестве средства платежа в безналичных расчетах через интернет, мобильную связь, в точках торговли и продаж [8]. Виртуальные деньги (криптовалюты) никак не привязаны к фиатным деньгам, призанным таковыми соглалсно действующему закону. Основой их появления является технология блокчейна, а сущностью - зашифрованные особым образом определенные математические коды и алгоритмы. Транзакции с виртуальными деньгами одновременно отражаются в распределенном реестре на тысячах компьютеров, поэтому внести в них какие-то изменения практически невозможно [2]. Эти деньги отличает скорость передачи, анонимность и необратимость транзакций. Таким образом, виртуальные деньги не имеют статуса законного средства платежа и не гарантируется ни одним государством, а по своей сути - это цифровое представление ценности, эмитируемое не центральным банком и не кредитным институтом, но которое используется как альтернатива деньгам. В мире насчитывается уже более 2000 видов криптовалют [9]. Мировой оборот криптовалют достиг 200 млрд долл. США, а для обеспечения их обращения 
создана новая инфраструктура (криптобиржи, криптообменники, криптофонды). Это свидетельствует о том, что внутри национальной денежной системы начинает функционировать сегмент, который со временем будет усиливать свое влияние на денежное обращение государства, но который не доступен национальному регулятору. Поэтому центральные банки ведущих стран мира сегодня озадачены созданием национальных виртуальных денег, которые будут обладать свойствами виртуальных денег, но которые будет контролировать и эмитировать центральный банк.

Цифровая трансформация экономики Российской Федерации определена в Указе Президента РФ от 9 мая 2017 г. № 203 «О Стратегии развития информационного общества в Российской Федерации на 2017 2030 годы». Во исполнение данного Указа разработана Федеральная программ «Цифровая экономика Российской Федерации», которая реализуется с 2017 года [10]. В 2020 году вышел федеральный закон № 259-Ф3 О цифровых финансовых активах и цифровой валюте. В соответствии со ст. 1 , п.3 Закона иифровой валютой признается совокупность электронных данных (цифрового кода или обозначения), содержащихся в информационной системе, которые предлагаются и (или) могут быть приняты в качестве средства платежа, не являющегося денежной единицей Российской Федерации, денежной единицей иностранного государства и (или) международной денежной или расчетной единицей, и (или) в качестве инвестиций и в отношении которых отсутствует лищо, обязанное перед каждым обладателем таких электронных данных, за исключением оператора и (или) узлов информачионной системы, обязанных только обеспечивать соответствие порядка выпуска этих электронных данных и осуществления в их отнотении действий по внесению (изменению) записей в такую информаиионную систему ее правилам [11]. Сегодня в правовом поле Российской Федерации понятие валюты используется как синоним денежного знака, т.е. законного средства платежа. Как следует из вышеприведенного определения, цифровая валюта не является денежной единицей Российской Федерации и, согласно закону не является платежным средством на территории страны [8]. Поэтому для введения цифрового рубля в денеж- ное обращение требуется более конкретное его законодательное определение.

Цифровая валюта центрального банка (Central Bank Digital Currency, CBDC) дополнит наличные и безналичные деньги цифровыми (фиатными), которые также станут обязательством центрального банка. Обращение цифрового рубля будет осуществляться в рамках дополнительной платежной инфраструктуры с меньшими рисками и затратами. Наличные и безналичные деньги будут свободно переводиться в цифровые и наоборот, а использование последних в онлайн и офлайн формате, в том числе без доступа к интернету, сделает очевидным их удобство, что вероятнее всего сократит потребность субъектов в наличных деньгах. В дальнейшем ожидается повышение кредитной активности за счет появления на кредитном рынке сегмента в цифровых деньгах.

С точки зрения денежных функций сравнительная характеристика цифрового рубля и рублей безналичных позволяет сделать вывод о том, что обе формы выполняют функции денег - меру стоимости, средства платежа, средства сбережения. В последней функции сбережение в форме банковского рублевого депозита создает возможность начисления процентов, тогда как цифровые деньги, хранящиеся в электронных кошельках, такой возможности лишены. Использование цифровых рублей в качестве средства платежа позволяет осуществлять расчеты как онлайн, так и офлайн, тогда как расчеты в безналичных рублях могут проводиться только онлайн. Достоинствами цифрового рубля являются: высокая скорость расчетов, небольшие издержки, надежность и безопасность использования в онлайни в офлайн-режиме. Следует отметить такое свойство цифровых рублей как конфиденциальность информации о потребителе, поскольку в данных о транзакции с цифровым рублем более ограничена информация о назначении платежа и его получателе, чем это требуют существующие платежные системы. Но, с другой стороны, перемещение цифровых денег можно отслеживать по цифровому коду. Это создает в цифровом сегменте условия для контроля государства за всеми платежными транзакциями, цифровыми кошельками, а также биометрическими персональными данными в сервисах цифрового профиля и единой биометрической системе. 
Функции участников проведения платежей в цифровых рублях

\begin{tabular}{|l|l|}
\hline \multicolumn{1}{|c|}{$\begin{array}{c}\text { Наименование } \\
\text { участника }\end{array}$} & \multicolumn{1}{c|}{ Выполняемые функции } \\
\hline Банк России & $\begin{array}{l}\text { 1. Эмиссия цифровых рубли } \\
\text { 2. Хранение цифровых кошельков } \\
\text { 3. Пополнение цифровых кошельков коммерческих банков средствами с кор- } \\
\text { респондентских счетов }\end{array}$ \\
\hline Коммерческие банки & $\begin{array}{l}\text { 1. Привлечение клиентов, осуществление взаимодействия с ними } \\
\text { 2. Открытие собственного цифрового кошелька в Банке России } \\
\text { 3. Открытие цифровых кошельков клиентов (физических и юридических лиц) } \\
\text { 4. Проведение операций перевода по поручению клиентов } \\
\text { 5. Проведение процедур противодействия отмыванию доходов и финансиро- } \\
\text { ванию терроризма }\end{array}$ \\
\hline Плательщики & $\begin{array}{l}\text { 1. Открытие цифрового кошелька в мобильном приложении банка } \\
\text { 2. Открытие цифрового кошелька на мобильном устройстве плательщика }\end{array}$ \\
\hline
\end{tabular}

Составлено автором по материалам [1].

$\mathrm{C}$ точки зрения механизма реализации цифровой валюты в денежном обращении Банк России предложил для обсуждения три модели, различающиеся составом субъектов, непосредственно взаимодействующих с центральным банком. По результатам широкого обсуждения проекта была выбрана модель внедрения цифрового рубля с участием коммерческих банков в роли посредников между владельцами электронных кошельков с цифровой валютой и ее эмитентом - Банком России. В результате функции участников платежей цифровой валютой распределились так, как это представлено в таблице.

Банк России как эмитент цифровых рублей будет поставлять их на цифровые кошельки коммерческих банков за счет списания безналичных рублей с корреспондентских счетов. Затем банк по желанию клиентов обменивает безналичные денежные средства на цифровые рубли, переводя их со своего цифрового кошелька на цифровой кошелек клиента. Эту операцию можно выполнить через мобильное приложение банка. Для расчетов оффлайн клиенту необходим второй кошелек, цифровые рубли на который банк переведет из его цифрового кошелька в мобильном приложении. Таким образом, введение цифрового рубля для физических лиц создает возможность перевести свои средства в цифровые кошельки, деньги в которых обеспечены всеми активами Банка России - эмитента цифровых рублей. Для реализации расчетов оффлайн пока нет определенностей в построении платежной системы для цифрового рубля - задача, над которой работает Банк России.
В области денежно-кредитного регулирования введение цифрового рубля создает неопределенность. Объем наличных денег в совокупной денежной массе Банк России может прямо регулировать через резервные фонды. Для косвенного регулирования безналичных денег Банк России использует норму резервирования как инструмент денежного мультипликатора денежных средств на банковских счетах. В условиях, когда предпочтения цифрового рубля физическими и юридическими лицами не известны, становится неизвестным и то, в какую сторону будут изменяться объемы отдельных денежных агрегатов в структуре денежной массы, являющейся объектом денежно-кредитного регулирования экономики со стороны центрального банка. Вероятно, Банк России будет лимитировать объемы обращения в цифровые рубли, что связано с определенными ограничениями перевода денег в цифровую форму.

Переход национальной валюты в цифровую форму сопряжен с высокой уязвимостью и потерями от киберпреступности. По данным МВФ убытки банков составляют до 300 млрд долл. в год [12]. По нашему мнению, это станет одной из основных проблем не только на стадии создания цифрового рубля, но также и в последующем процессе его функционирования, поскольку схемы и технологии киберпреступлений также развиваются и постоянно совершенствуются. Однако, то обстоятельство, что цифровые деньги - это обязательство центрального банка, будет стимулировать субъектов к преодолению барьера к их использованию. 
Нам видится еще ряд проблем, которые могут возникнуть с введением цифровых денег в части обеспечения ликвидности коммерческих банков и выполнения ими экономических нормативов; планирования банками ресурсов для срочного кредитования; использования цифровых беспроцентных денег для инвестирования в инструменты финансового рынка и другие. Но все они пока имеют отсроченный характер. Текущей задачей для коммерческих банков нам видится активная организация обеспечения финансовой грамотности разных категорий субъектов: населения, предпринимателей и организаций с тем, чтобы быть ближе к настоящим и будущим клиентам для сохранения и наращивания клиентской базы. Коммерческие банки могут создавать и реализовывать совместные с экономическими вузами программы просвещения и повышения финансовой грамотности как физических, так и юридических лиц клиентов банка. Близость к клиенту позволит укрепить доверие к банку и, в определенной степени, управлять поведенческими реакциями на введение новой формы денег.

\section{Заключение}

Можно заключить, что современные наука и технологии способствовали переводу всех экономических областей и процессов в цифровое русло, результатом чего стало появление цифровой валюты в форме электронных денег и виртуальных денег (децентрализованных и централизованных). Децентрализованные деньги (криптовалюты) появились стихийно вне области функционирования банковских систем и кредитных организаций. Однако растущий рынок этих денег вызывает беспокойство у центральных банков большинства стран в силу по- следующего давления на государственную денежную систему, будущих проблем в денежно-кредитном регулировании и определенных рисков для коммерческих банков. В настоящее время центральные банки многих стран, включая Россию, разрабатывают проекты введения национальных цифровых денег. Банк России в процессе введения цифрового рубля определил 7 этапов. На первом этапе был подготовлен доклад «Цифровой рубль» для широкого обсуждения и общественных консультаций. На втором этапе рабочая группа Банка России обрабатывала поступившие по теме замечания, в результате чего была выбрана модель реализации с участием в операциях с цифровым рублем коммерческих банков в качестве посредников между Банком России и владельцами цифровых кошельков. Третий этап будет посвящен разработке концепции цифрового рубля. На четвертом этапе планируется создание платформы цифрового рубля, на пятом - ее пилотные испытания. Шестой этап включает анализ и оценку результатов испытания, а седьмой - определение целесообразности и разработку процесса введения цифрового рубля в денежное обращение России. Принцип постепенности, которым руководствуется Банк России, поможет обнаруживать возникающие риски, которые в силу высокой неопределенности не являются очевидными на начальных этапах разработки новой формы цифровых денег на базе распределенного реестра цифровых транзакций, которые дополнят электронные деньги, функционирующие на базе сетей и на базе карт. Проектирование цифровых денег и опыт в этой области других стран станут эмпирической базой исследований и дальнейшего развития теории денег и денежного обращения.

\section{Библиографический список}

1. Цифровой рубль. Доклад для общественных консультаций. М.: Банк России, 2020. 48 с.

2. Обзор по криптовалютам ICO (INTIAL COIN OFFERING) и подходам к их регулированию (декабрь 2017. Москва) [Электронный ресурc]. URL: https://www.cbr.ru (дата обращения: 07.08.2021).

3. Киселев А. Есть ли будущее у цифровых валют центральных банков?: Аналитическая записка. М.: Банк России, 2019. 23 с.

4. Пшеничников В.В. Перспективы эмиссии цифрового рубля и его функционирования в платежном обороте страны // Научно-технические ведомости СПбГПУ. Экономические науки. 2020. Т. 13. № 6. С. 101-109.

5. Андрюшин С.А. Цифровая валюта центрального банка как третья форма денег государства // Актуальные проблемы экономики и права. 2021. Т. 15. № 1. С. 54-76. 
6. Чеканов П.Е. Перспективы и риски эмиссии цифрового рубля Банком России // Азимут научных исследований: экономика и управление. 2021. Т. 10. № 2(35). С. 383-388.

7. Синельникова-Мурылева Е.В. Цифровые валюты центральных банков: потенциальные риски и выгоды // Вопросы экономики. 2020. № 4. С. 147-159.

8. Федеральный закон «О Центральном банке Российской Федерации (Банке России)» от 10.07.2002 № 86-ФЗ (в ред. от 20.07.2020).

9. Криптоэкономика / А.Д. Левашенко, И.С. Ермохин, Зубарев и др. М.: Издательский дом «Дело» РАНХиГС, 2019. 60 с.

10. Федеральная программа «Цифровая экономика Российской Федерации», утв. Правительством РФ 28 июля 2017 г. № 1632-р [Электронный ресурс]. URL:http://www.library.fa.ru/files/digital-economy.pdf (дата обращения: 15.11.2021).

11. Федеральный закон «О цифровых финансовых активах, цифровой валюте и о внесении изменений в отдельные законодательные акты Российской Федерации» от 31.07.2020 N 259-Ф3 (последняя редакция).

12. The 2020 McKinsey Global Payments Report 02.10.2020 [Электронный pecypc]. URL: https:// www. mckinsey.com/ (дата обращения: 11.08.2021). 